\title{
Routine infant immunization with the 7- and 13-valent pneumococcal conjugate vaccines: current perspective on reduced-dosage regimens
}

\author{
Teresa Jackowskaํ, Justyna Pluta
}

1Department of Pediatrics, The Medical Centre of Postgraduate Education, Warsaw, Poland

2Pfizer Poland

Submitted: 1 July 2011

Accepted: 5 December 2011

Arch Med Sci 2012; 8, 3: 542-548

DOI: 10.5114 /aoms.2012.29410

Copyright @ 2012 Termedia \& Banach

\begin{abstract}
The 7 and 13-valent pneumococcal conjugate vaccines are mostly used in routine infant immunizations to prevent the development of pneumococcal disease. Currently, the dosing schedule approved and recommended for PCV7 and PCV13 in infants is 3 primary doses followed by a booster dose in the second year of life. However, a number of countries use a 2-dose only primary series with a booster dose in the second year of life. This review is aimed at providing the reader with a broad perspective on the currently available evidence which supports the clinical use of such reduced dosing schedules for the PCV7 and PCV13 vaccines. Recent evidence has been able to promulgate the immunogenicity and in some cases the effectiveness of the reduced dosing schedule for these vaccines. These findings may reduce costs as well as minimize supply and administration problems relating to the provision of the pneumococcal conjugated vaccines (PCVs). However, some caution is warranted since some inferior data have emerged with regards to the antibody immune response to certain pneumococcal serotypes following the implementation of such reduced dosing regimens. In addition, it is proposed that prospective surveillance be undertaken in all countries which have adopted the reduced-dosage immunization programs. This review may go some way in educating healthcare practitioners and healthcare policy decision makers at large.
\end{abstract}

Key words: 7-valent, 13-valent, pneumococcal, vaccine, schedule.

\section{Introduction}

Streptococcus pneumoniae (S. pneumoniae) has been implicated as an important cause of otitis media, sinusitis, pneumonia, and invasive pneumococcal diseases (IPD) such as meningitis, bacteremia, and bacteremic pneumonia [1]. Streptococcus pneumoniae is a major cause of morbidity and mortality worldwide, in young children, individuals with chronic cardiopulmonary disease, the elderly, and immunocompromised individuals of all ages [2-5]. As a result, the prevention of pneumococcal disease is an important public health care goal.

The 7 and 13-valent pneumococcal conjugate vaccines are used commonly in routine infant immunizations to prevent the development of pneumococcal disease. In the USA and in Europe, the 7-valent pneumococcal conjugate vaccine (PCV7) is licensed for use among infants. In Feb-

\author{
Corresponding author: \\ Justyna Pluta PhD \\ Pfizer Poland \\ 17 B Postepu \\ 02-676 Warsaw, Poland \\ E-mail: \\ justyna.pluta@pfizer.com
}


ruary 2010, the Advisory Committee on Immunization Practices (ACIP) issued recommendations for the usage of a newly licensed 13-valent pneumococcal conjugate vaccine (PCV13) [6]. PCV13 contains the seven serotypes in PCV7 $(4,6 \mathrm{~B}, 9 \mathrm{~V}, 14,18 \mathrm{C}$, $19 \mathrm{~F}, 23 \mathrm{~F})$ and six additional serotypes (1, 3, 5, 6A, 7F, 19A). PCV13 was licensed by European Medicines Agency (EMA) in the year 2009. This vaccine is approved for use in children aged between 6 weeks and 59 months and is considered by many health care practitioners as a successor to PCV7.

There is much evidence to show that the development of conjugate vaccines and their adoption within routine childhood immunization programs has presented a major step forward in preventing invasive pneumococcal disease. Whilst this is an important advancement, there is still much discussion about the exact immunization schedules which should be followed to prevent the occurrence of invasive pneumococcal disease. In some countries, infants below 6 months of age receive their first primary dose of PCV7 or PCV13 followed by two additional primary doses of the same vaccine at intervals of approximately 2 months. These primary doses are then followed by a fourth booster dose in the child's second year of life [2]. In such countries, the ACIP adopted the manufacturers' recommended schedule since the pre-licensure development program for PCV7 did not include studies to assess the immunogenicity of a $2+1$ reduced dosage schedule [6]. However, in a number of other countries, a reduced 2 -dose schedule $(2+1)$ for this vaccines has been adopted [7-9].

Recent evidence has been able to promulgate the effectiveness of the $2+1$ reduced dosing schedule for PCV7. Similarly, current relevant reports indicate that a reduced $2+1$ dosing schedule for PCV13 may also be effective. However, the number of reports indicating the latter is scarcer. This review is aimed at providing the reader with a perspective on the currently available evidence which supports the clinical use of reduced $2+1$ dosing schedules for PCV7 as well as PCV13. To this end, an extensive systematic literature review was undertaken pertaining to the immunogenicity and effectiveness of the reduced-dosage regimens of PCV7 and PCV13. Information was collated from: expert-opinion articles located within EMBASE, PubMed and The Cochrane Library; additional information obtained from article reference lists; and from the Internet.

This review is aimed at informing the reader about whether pneumococcal immunization schedules may be simplified and yet still ensure effective immunity. This issue has remained of interest to some medical practitioners since the routine childhood vaccination schedule in many countries is becoming increasingly crowded. The number of vaccine injections that infants must receive as well as the associated costs has slowed the immunization rate in many geographical areas [7]. Such knowledge may also be used in preventing a potential shortage in the supply of the pneumococcal conjugate vaccine. The latter has been shown to greatly influence the type of dosing regimen which is used [10-13]. This review may also go some way in defining vaccination policies which are used in areas of the world which have not yet introduced the vaccine routinely. Furthermore, it may also educate medical personnel who may be confused by seemingly conflicting advice relating to vaccine schedules. In addition, this article may also shed some light on the processes which have been used for evaluating the efficacy and safety of the pneumococcal vaccines.

\section{7-valent pneumococcal conjugate vaccine (PCV7)}

Immunogenicity of the reduced-dose schedule in children

A number of reports have been published which investigated the immunogenicity following a $2+1$ reduced dosage regimen and compared the results with a 3+1 dosage schedule for PCV7. The studies are summarized in Table I.

Rennels et al. assessed the IgG antibody titer response when healthy 2-month-old infants were immunized with the PCV7 vaccine [16]. Employing an open-label, self-controlled study with a cohort study group of 212 subjects, the investigators showed that serotype-specific IgG GMC values for serotypes $6 \mathrm{~B}, 9 \mathrm{~B}$ and $23 \mathrm{~F}$ were lower for the abbreviated PCV7 schedule compared to after three primary doses.

Ekström et al. employed an open-label, self-controlled study design $(n=56)$ to assess serotypespecific IgG GMC values after two and three primary doses of PCV7, respectively [17]. They reported that antibody responses following two doses were generally lower than after three doses for serotypes $6 \mathrm{~B}$ and $23 \mathrm{~F}$.

The immunogenicity and safety of PCV7 used in a 2+1 immunization schedule (3, 5, 11 months) were also studied in pre-term infants (PT). Esposito et al. conducted a study in which 92 infants were enrolled in an open-label, uncontrolled clinical study [18]. An antibody titer concentration $\geq 1.0 \mu \mathrm{g} / \mathrm{ml}$ was usually reached after the third dose. Importantly, by comparing previously published results obtained with the 4-dose schedule, the authors were able to show that the reduced 3-dose schedule was comparable in terms of immunogenicity [16, 19-22].

In 2005 Käyhty et al. published the results of a study which aimed at assessing the immunogenicity of PCV7 [23]. The primary vaccination con- 
Table I. Summary of studies relating to immunogenicity of pneumococcal vaccines administered according to a $2+1$ or a $3+1$ schedule

\begin{tabular}{|c|c|c|c|c|}
\hline Study design & $\begin{array}{l}\text { Number } \\
\text { of subjects }(n)\end{array}$ & $\begin{array}{c}\text { Dose } \\
\text { assessed }\end{array}$ & Results & Reference \\
\hline $\begin{array}{l}\text { Open-label } \\
\text { self-controlled }\end{array}$ & 212 & Primary & $\begin{array}{l}\text { Serotype-specific antibodies towards } 6 \mathrm{~B}, 9 \mathrm{~B} \\
\text { and } 23 \mathrm{~F} \text { lower in } 2+1 \text { compared to } 3+1 \text { schedule }\end{array}$ & {$[16]$} \\
\hline $\begin{array}{l}\text { Open-label } \\
\text { self-controlled }\end{array}$ & 56 & Primary & $\begin{array}{l}\text { Serotype-specific antibodies towards } 6 \mathrm{~B} \\
\text { and } 23 \mathrm{~F} \text { lower in } 2+1 \text { compared to } 3+1 \text { schedule }\end{array}$ & {$[17]$} \\
\hline $\begin{array}{l}\text { Open-label } \\
\text { uncontrolled }\end{array}$ & 92 & Primary & $\begin{array}{l}\text { Similar serotype-specific antibodies } \\
\text { in } 2+1 \text { compared to } 3+1 \text { schedule }\end{array}$ & {$[18]$} \\
\hline $\begin{array}{l}\text { Open-label } \\
\text { uncontrolled }\end{array}$ & 99 & $\begin{array}{l}\text { Primary; } \\
\text { booster }\end{array}$ & $\begin{array}{l}\text { Serotype-specific antibody towards } 6 \mathrm{~B} \text { lower } \\
\text { in } 2+1 \text { compared to } 3+1 \text { schedule }\end{array}$ & {$[23]$} \\
\hline $\begin{array}{l}\text { Randomized } \\
\text { controlled }\end{array}$ & 775 & $\begin{array}{l}\text { Primary; } \\
\text { booster }\end{array}$ & $\begin{array}{l}\text { Serotype-specific antibodies towards } 6 \mathrm{~B}, 14 \\
\text { and } 23 \mathrm{~F} \text { lower in } 2+1 \text { compared to } 3+1 \text { schedule }\end{array}$ & [24-26] \\
\hline $\begin{array}{l}\text { Open-label } \\
\text { uncontrolled }\end{array}$ & 250 & $\begin{array}{l}\text { Primary; } \\
\text { booster }\end{array}$ & $\begin{array}{l}\text { Serotype-specific antibodies towards } 6 \mathrm{~B} \\
\text { and } 19 \mathrm{~F} \text { lower in } 2+1 \text { compared to } 3+1 \text { schedule }\end{array}$ & [27] \\
\hline $\begin{array}{l}\text { Open-label } \\
\text { uncontrolled }\end{array}$ & 321 & Primary & $\begin{array}{l}\text { Serotype-specific antibodies towards } 6 \mathrm{~B} \\
\text { and } 23 \mathrm{~F} \text { lower in } 2+1 \text { compared to } 3+1 \text { schedule }\end{array}$ & [28] \\
\hline $\begin{array}{l}\text { Randomized } \\
\text { controlled }\end{array}$ & 367 & $\begin{array}{l}\text { Primary; } \\
\text { booster }\end{array}$ & $\begin{array}{l}\text { Serotype-specific antibodies towards } 6 \mathrm{~B}, 18 \mathrm{C} \\
\text { and } 23 \mathrm{~F} \text { lower in } 2+1 \text { compared to } 3+1 \text { schedule }\end{array}$ & [7] \\
\hline Non-inferiority & $N D^{b}$ & $\begin{array}{l}\text { Primary; } \\
\text { booster }\end{array}$ & $\begin{array}{l}\text { Direct comparison of PCV7 and PCV13; slightly lower } \\
\text { serotype-specific antibodies towards 6B and 23F }\end{array}$ & {$[44]^{a}$} \\
\hline
\end{tabular}

${ }^{a}$ Authors of the report are not disclosed, ${ }^{b} N D$ denotes not documented

sisted of 2 doses (administered at 3 and 5 months of age) and a third booster dose given at 12 months of age. Käyhty et al. concluded that PCV7 was immunogenic when given in the abbreviated schedule. Importantly, the results suggested that the pneumococcal antibody concentrations following primary as well as booster doses were comparable to the results which were obtained with the 4-dose schedule.

Russell et al. investigated several pneumococcal vaccination strategies for resource-poor countries using a randomized controlled clinical study [2426]. The cohort group consisted of healthy Fijian infants and the investigators showed that two primary doses of PCV7 achieved GMC levels which were lower for serotypes $6 \mathrm{~B}, 14$, and $23 \mathrm{~F}$ compared to the 3-dose primary schedule. However, the investigators reported that this difference was small. In 2010, the same authors showed that the immune response towards all serotypes following a 2 or 3 primary series was not statistically different but that again the immune responses were lower for serotypes $6 \mathrm{~B}, 14$, and $23 \mathrm{~F}$ following the abbreviated immunization schedule.

In an open-label, uncontrolled study, Rodenburg et al. evaluated the immunogenicity of PCV7 following a $2+1$ or $3+1$ dosing schedule [27]. The authors reported that for serotypes 6B and 19F, significantly lower antibody levels were reported for the reduced dosage regimen compared to the $3+1$ dosing schedule.
By undertaking various open-label uncontrolled clinical studies, Goldblatt et al. investigated the immunogenicity of 2+1 PCV7 dosing schedules [28]. The authors showed that the immune response for serotypes $6 \mathrm{~B}$ and $23 \mathrm{~F}$ was lower for the abbreviated PCV7 schedule compared to subjects who had received 3 primary doses.

Givon-Lavi et al. used randomized controlled trials to design and compare the immune response in healthy infants following a two-dose and a threedose primary series [7]. The proportion of subjects enrolled in the study who received post-primary serotype specific $\lg G$ antibody concentrations $\geq 0.35$ $\mu \mathrm{g} / \mathrm{ml}$ was significantly greater after three primary doses for serotypes $6 \mathrm{~B}, 14,18 \mathrm{C}$ and $23 \mathrm{~F}$ compared to two primary doses. Post-booster analysis further revealed that serotype-specific IgG GMC values were significantly greater for serotypes $6 \mathrm{~B}, 18 \mathrm{C}$ and $23 \mathrm{~F}$ in the $3+1$ group compared to those in the $2+1$ group.

For all the studies mentioned above, the immune response following primary doses for the $2+1$ or $3+1$ PCV7 dosing schedules were generally similar for serotypes 4, 9V, 14, 18C and 19F. However, nearly all of the literature indicated that post-dose two response rates, as well as IgG GMC values, for serotypes $6 \mathrm{~B}$ and $23 \mathrm{~F}$ were significantly lower compared with post-dose three responses. Furthermore, an analysis of antibody values following the booster dose generally indicates that the abbreviated dosing schedule of PCV7 achieves comparable antibody levels to those achieved with a 3+1 dosing schedule. 
Effectiveness of the reduced-dose schedule $(2+1)$ in children

There is compelling evidence which confirms the clinical efficacy of the reduced dosage schedule in the USA, Canada and Europe. This section of the review presents a summary of the reports which document the effectiveness of the reduced-dosage regimen (2+1). The studies are summarized in Table II.

In Canada, a 7-valent pneumococcal conjugate vaccine was licensed for use in 2001. A case-control study on vaccine effectiveness (VE) against IPD was conducted. The investigators reported that in Canada the effectiveness of the $2+1$ dosing schedule for PCV7 was $100 \%$, which is similar to the $3+1$ dosing schedule for the same vaccine $[29,30]$.

The effectiveness of the reduced-dosage $2+1$ regimen for PCV7 was estimated in a retrospective matched case-control study [31]. The investigators determined that the abbreviated 2+1 PCV7 dosage regimen resulted in $98 \%$ effective immunity against vaccine serotype-related invasive pneumococcal disease. The authors concluded that this result was comparable to that obtained with a four-dose PCV7 vaccination series.

In Denmark, the Danish Childhood Vaccination Registry used surveillance and vaccine uptake data to estimate the effectiveness of the reduced-dosage schedule for PCV7 [32]. The authors reported that the administration of PCV7 was followed by a marked decline in the incidence of IPD in both vaccinated and non-vaccinated individuals. The results were comparable to those previously obtained with the $3+1$ dosing regimen for PCV7.

A government-sponsored reduced-dose PCV7 vaccination program was also introduced in Italy $[33,34]$. Statistically significant declines were seen in all-cause pneumonia, pneumococcal pneumonia, and otitis media between the cohorts. The observed significant reduction in pneumococcal disease was non-inferior to that observed with the $3+1$ dosing schedule [35-37].

In 2006, a compulsory, free-of-charge, reduceddose PCV7 vaccination program was introduced in Poland. Patrzałek et al. investigated the influence of pneumococcal vaccination on the radiologically confirmed pneumonia admission rates in the hospital [8]. The results compare well with the $3+1$ PCV7 dosing schedule [35-37].

The PCV7 vaccine was introduced into the routine childhood immunization program of the UK in 2006. The vaccine is given as a 3-dose schedule at 2, 4 and 13 months of age. Since the vaccine was introduced, there has been a marked reduction in the rate of cumulative increase of IPD cases caused by the 7 serotypes in PCV7 [38]. Whilst the early estimate of VE was $84 \%$, the paper highlighted that protection against serotype $6 \mathrm{~B}$ was reduced and serotype replacement was also evident. The investigators also indicated that VE of the reduceddosage schedule for PCV7 is expected to increase once the impact of the booster dose is taken into consideration.

Table II. Summary of studies relating to the effectiveness of pneumococcal vaccines administered according to a $2+1$ or a $3+1$ schedule

\begin{tabular}{|c|c|c|c|}
\hline Study design & Target population & Results & Reference \\
\hline $\begin{array}{l}\text { Surveillance of hospital } \\
\text { discharge records }\end{array}$ & $\begin{array}{l}\text { Children aged } \\
<5 \text { years }\end{array}$ & $\begin{array}{l}\text { High child immunization coverage; } \\
2+1 \text { dosing schedule offered } 100 \% \text { effective immunity }\end{array}$ & {$[29,30]$} \\
\hline $\begin{array}{l}\text { Retrospective matched } \\
\text { case-control study }\end{array}$ & $\begin{array}{l}\text { Children aged } \\
\text { 3-59 months }\end{array}$ & $2+1$ dosing schedule offered $98 \%$ effective immunity & [31] \\
\hline $\begin{array}{l}\text { Surveillance of vaccination } \\
\text { registry }\end{array}$ & $\begin{array}{l}\text { Children aged } \\
<5 \text { years }\end{array}$ & $\begin{array}{l}\text { Decline in IPD following the } 2+1 \text { schedule similar } \\
\text { to results obtained with the } 3+1 \text { dosing regime }\end{array}$ & [32] \\
\hline $\begin{array}{l}\text { Surveillance of hospital } \\
\text { admissions }\end{array}$ & $\begin{array}{l}\text { Children aged } \\
<2 \text { years }\end{array}$ & $\begin{array}{l}\text { Significant decline in pneumococcal disease following } \\
\text { the } 2+1 \text { schedule which was non-inferior compared } \\
\text { to the } 3+1 \text { dosing schedule }\end{array}$ & {$[33,34]$} \\
\hline $\begin{array}{l}\text { Surveillance of radiologically } \\
\text { confirmed pneumonia } \\
\text { admission rates } \\
\text { in a hospital }\end{array}$ & $\begin{array}{l}\text { Children aged } \\
<5 \text { years }\end{array}$ & Significant decline in pneumonia hospitalization rates & [8] \\
\hline National surveillance & $\begin{array}{l}\text { Children aged } \\
<5 \text { years }\end{array}$ & $\begin{array}{l}\text { Significant decline in IPD cases; reduced protection } \\
\text { against serotype } 6 \mathrm{~B} \text { and evidence of serotype replacement }\end{array}$ & $t^{[38]}$ \\
\hline National surveillance & $\begin{array}{l}\text { Children aged } \\
<2 \text { years }\end{array}$ & Vaccine serotype-related IPD decreased by $86 \%$ & {$\left[16,39^{\star}\right]$} \\
\hline National surveillance & $\begin{array}{l}\text { Children aged } \\
<5 \text { years }\end{array}$ & $\begin{array}{l}\text { High vaccine coverage and low IPD incidence rates; } \\
\text { vaccine effectiveness estimated at } 74 \%\end{array}$ & [40] \\
\hline
\end{tabular}

${ }^{*}$ Authors of the report are not disclosed 
The Belgian national immunization program began in 2007 with a 2, 4, 12 vaccination schedule [39]. Surveillance reports compiled by the Belgium Public Institute of Health indicate that the incidence of vaccine serotype-related IPD in children $<2$ years of age decreased by $86 \%$ [16].

In Norway, a national immunization program for PCV7 was implemented in July 2006. The immunization program follows a 3-dose schedule given at 3, 5 and 12 months of age. Cases of IPD were surveyed and Vestrheim et al. published the results of this surveillance and reported a decrease in IPD in all age groups under the age of 5 years [40]. Furthermore, the incidence of IPD and vaccine serotype IPD was reported to have declined significantly in almost all age groups. Notably, the effectiveness of the vaccination program in children aged $<2$ years was $74 \%$ [40-42].

The studies mentioned above indicate that the $2+1$ dosing schedule for PCV7 is effective in immunizing against invasive and non-invasive pneumococcal disease. This is especially the case in countries which are characterized by good primary series uptake, compliance, and implementation of a catchup program in the older infant or children population groups. Undoubtedly, long-term prospective surveillance programs need to be maintained in order to determine the long-term beneficial effects of the reduced-dose PCV7 schedule.

\section{3-valent pneumococcal conjugate vaccine (PCV13)}

Immunogenicity data from the PCV13 clinical development program

For the 7 common serotypes in PCV13 and PCV7 $(4,6 \mathrm{~B}, 9 \mathrm{~V}, 14,18 \mathrm{C}, 19 \mathrm{~F}, 23 \mathrm{~F})$, it is already known that PCV13 is comparable to PCV7 when administered in a 3+1 dosing schedule [43]. Since PCV7 has been documented to be effective when given in a $2+1$ dosing schedule, a few studies have compared the immunogenicity data when PCV13 and PCV7 are given in accordance with this dosing regimen $[8,9$, $12,19]$.

To the best of our knowledge, only two non-inferiority clinical trials have been undertaken in order to assess the immunogenicity responses following a $2+1$ dosing schedule of the PCV13 and PCV7 vaccines [44]. For the 2 primary doses of PCV13, slightly lower polysaccharide-binding antibody titer concentrations were obtained for serotypes $6 \mathrm{~B}$ and $23 \mathrm{~F}$, whilst the immune response for the remaining 5 serotypes was comparable between the two vaccines. For the 7 common serotypes in PCV13 and PCV7, similar immune responses were obtained following completion of the 2 primary doses and the booster dose. Thus, it is tentatively expected that, for the 7 common serotypes, the clinical efficacy of PCV7 and PCV13 will be similar.
For the 6 additional serotypes, the percentage of infants achieving a clinically effective antibody threshold concentration $\geq 0.35 \mu \mathrm{g} / \mathrm{ml}$ after the second dose ranged from $79.2 \%$ to $98.5 \%$. Post-booster antibody GMC levels in a 2+1 schedule were comparable to those achieved with a $3+1$ schedule. These results indicate that PCV13 can be given safely and effectively in a reduced-dosage schedule. This strategy could provide protection against a broader spectrum of pneumococcal serotypes as well as improving herd immunity.

\section{Conclusions}

Some countries have adopted the $3+1$ dosing schedule for PCV7. However, as shown above, clinical data are now available which demonstrate that PCV7 can be safely and effectively administered in a reduced $2+1$ dosing regimen. With regards to PCV13, the manufacturer's recommended dosing schedule is also $3+1$. The immunogenicity data which have been obtained for PCV13 following two primary doses as well as after a third booster dose tentatively indicate that this vaccine may be administered safely and effectively in a reduced-dosage schedule. We propose that administering the PCV in a reduced-dosage regimen is advantageous to the alternative $3+1$ dosing regimen and that indeed this should be adopted by the countries who have implemented the latter regime. However, some caution is warranted since some inferior data have emerged with regards to the antibody immune response to certain pneumococcal serotypes. The reduced-dosage regimen may go some way in reducing costs as well as minimizing supply and administration problems relating to the provision of the pneumococcal conjugated vaccines. Nonetheless, caution is warranted since a reduced dosing regimen could result in compliance failures having a larger than expected effect on population immunity. However, such concerns relating to compliance may need to be investigated thoroughly in order to reach firm conclusions. Furthermore, it is noteworthy that prospective continued surveillance of the occurrence of invasive pneumococcal disease should take place in all countries which have adopted PCV immunization programs in order to fully clarify the clinical influence of the PCV reduceddosage regimen on pneumococcal-induced morbidity and mortality. This would allow for the detection of any increase in the rate of vaccine failure with either regimen and may in turn educate medical practitioners and healthcare policy decision makers.

\section{Acknowledgments}

Teresa Jackowska - lectures for physicians sponsored by Pfizer Poland. Justyna Pluta is permanently 
employed by Pfizer Poland. The authors thank Proper Medical Writing (infrared group s.c.) for technical and language assistance in the preparation of this paper. Proper Medical Writing was sponsored by Pfizer Poland.

\section{References}

1. CDC. Prevention of pneumococcal disease: recommendations of the Advisory Committee on Immunization Practices (ACIP). MMWR 1997; 46: 1-24.

2. CDC. Preventing pneumococcal disease among infants and young children: recommendations of the Advisory Committee on Immunization Practices (ACIP). MMWR 2000; 49: 1-38.

3. CDC. Invasive pneumococcal disease in young children before licensure of 13-valent pneumococcal conjugate vaccine - United States, 2007. MMWR 2010; 59: 253-7.

4. Robinson K, Baughman W, Rothrock G, et al. Epidemiology of invasive Streptococcus pneumoniae infections in the United States, 1995-1998: opportunities for prevention in the conjugate vaccine era. JAMA 2001; 285: 1729-35.

5. Pilishvili T, Lexau C, Farley MM, et al. Sustained reductions in invasive pneumococcal disease in the era of conjugate vaccine. J Infect Dis 2010; 201: 32-41.

6. CDC. Licensure of a 13-valent pneumococcal conjugate vaccine (PCV13) and recommendations for use among children - Advisory Committee on Immunization Practices (ACIP). MMWR 2010; 59: 258-61.

7. Givon-Lavi N, Greenberg D, Dagan R. Immunogenicity of alternative regimens of the conjugated 7-valent pneumococcal vaccine: a randomized controlled trial. Pediatr Infect Dis J 2010; 29: 756-62.

8. Patrzałek M, Albrecht P, Sobczyński M. Significant decline in pneumonia admission rate after the introduction of routine $2+1$ dose schedule heptavalent pneumococcal conjugate vaccine (PCV7) in children under 5 years of age in Kielce, Poland. Eur J Clin Microbiol Infect Dis 2010; 29: 787-92.

9. Immunisation against infectious disease - 'The Green Book', 2007. http://www.dh.gov.uk/en/Publications andstatistics/Publications/PublicationsPolicyAndGuidance/ DH_079917 (accessed 5 June 2011).

10. Centers for disease control and prevention. Notice to readers: limited supply of pneumococcal conjugate vaccine: suspension of recommendation for fourth dose. MMWR 2004; 53; 108-9.

11. Freed GL, Davis MM, Clark SJ. Variation in public and private supply of pneumococcal conjugate vaccine during a shartage. J Am Med Assoc 2003; 289: 575-8.

12. Centers for disease control and prevention. Limited supply of pneumococcal conjugate vaccine. MMWR 2003; 52: 1234.

13. Centers of disease control and prevention. Preventing pneumococcal disease among infants and young children: recommendations of the Advisory Committee on Immunization Practices (ACIP). MMWR 2000; 49(RR9).

14. World health organisation. WHO Technical Report Series, number 927. World health organization, Geneva, Switzerland, 2005.

15. Feavers I, Knezevic I, Powell M, Griffiths E. Challenges in the evaluation and licensing of new pneumococcal vaccines, 7-8 July 2008, Ottawa, Canada. Vaccine 2009; 27: $3681-8$.

16. Rennels MB, Edwards KM, Keyserling HI, et al. Safety and immunogenicity of heptavalent pneumococcal vaccine conjugated to $\mathrm{CRM}_{197}$ in United States infants. Pediatrics 1998; 101: 604-11.

17. Ekström N, Ahman H, Verho J, et al. Finnish Otitis Media Strudy Group. Kinetics and avidity of antibodies evoked by heptavalent pneumococcal conjugate vaccines PncCRM and PncOMPC in the Finnish Otitis Media Vaccine Trial. Infect Immun 2005; 73: 369-77.

18. Esposito S, Pugni L, Bosis S, et al. Immunogenicity, safety and tolerability of heptavalent pneumococcal conjugate vaccine administered at 3, 5 and 11 months post-natally to pre- and full-term infants. Vaccine 2005; 23: 1703-8.

19. Whitney CG, Farley MM, Hadler J, et al. Decline in invasive pneumococcal disease after the introduction of proteinpolysaccharide conjugate vaccine. N Engl J Med 2003; 348: 1737-46.

20. Eskola J, Kilpi T, Palmu A, et al. Efficacy of a pneumococcal conjugate vaccine against acute otitis media. N Engl J Med 2001; 344: 403-9.

21. Black S, Shinefield H, Fireman B, et al. Efficacy, safety and immunogenicity of heptavalent pneumococcal conjugate vaccine in children. Northern California Kaiser Permananet Vaccine Study Center Group. Pediatr Infect Dis J 2000; 19: 187-95.

22. Käyhty $\mathrm{H}$, Ahman $\mathrm{H}$, Eriksson $\mathrm{K}$, et al. Pneumococcal conjugate vaccine (PNCCRM) is immunogenic when administered at 3, 5 and 12 months of age. In: Proceedings of the 21st annual meeting of the European Society for Paediatric Infectious Diseases, 2003.

23. Käyhty H, Ahman H, Eriksson K, et al. Immunogenicity and tolerability of a heptavalent pneumococcal conjugate vaccine administered at 3, 5 and 12 months of age. Pediatr Infect Dis J 2005; 24: 108-14.

24. Russell FM, Balloch A, Tang MLK, et al. Immunogenicity following one, two, or three doses of the 7-valent pneumococcal conjugate vaccine. Vaccine 2009; 27: 5685-91.

25. Russell FM, Licciardi PV, Balloch A, et al. Safety and immunogenicity of the 23-valent pneumococcal polysaccharide vaccine at 12 months of age, following one, two, or three doses of the 7-valent pneumococcal conjugate vaccine in infancy. Vaccine 2010; 28: 3086-94.

26. Russell FM, Carapetis JR, Burton RL. Opsonophagocytic activity following a reduced dose 7-valent pneumococcal conjugate vaccine infant primary series and 23 -valent pneumococcal polysaccharide vaccine at 12 months of age. Vaccine 2010; 29: 535-44.

27. Rodenburg GD, van Gils EJM, Veenhoven RH, et al. Comparability of antibody response to a booster dose of 7 -valent pneumococcal conjugate vaccine in infants primed with either 2 or 3 doses. Vaccine 2010; 28: 1391-6.

28. Goldblatt G, Southern J, Ashton L, et al. Immunogenicity of a reduced schedule of pneumococcal conjugate vaccine in healthy infants and correlates of protection for serotype 6B in the United Kingdom. Pediatr Infect Dis J 2010; 29: $1-5$.

29. De Wals P, Robin E, Fortin E, et al. Pneumonia after implementation of the pneumococcal conjugate vaccine program in the province of Quebec, Canada. Pediatr Infect Dis J 2008; 27: 963-8.

30. Deceuninck G, De Wals P, Boulianne N, et al. Effectiveness of pneumococcal conjugate vaccine using a $2+1$ infant schedule in Quebec, Canada. Pediatr Infect Dis J 2009; 29: 546-9.

31. Whitney CG, Pilishvili T, Farley MM, et al. Effectiveness of seven-valent pneumococcal conjugate vaccine against invasive pneumococcal disease: a matched case control study. Lancet 2006; 368: 1495-502.

32. Harboe ZB, Valentiner-Branth P, Benfield TL, et al. Early effectiveness of heptavalent conjugate pneumococcal 
vaccination on invasive pneumococcal disease after the introduction in the Danish Childhood Immunization Programme. Vaccine 2010; 28: 26427.

33. Ansaldi F, Sticchi L, Durando P, et al. Decline in pneumonia and acute otitis media after the introduction of childhood pneumococcal vaccination in Liguria, Italy. J Int Med Res 2008; 36: 1255-60.

34. Durando P, Crovari P, Ansaldi, F, et al. Universal childhood immunization against Streptococcus pneumoniae: the five-year experience of Liguria Region, Italy. Vaccine 2009; 27: 3459-62.

35. Crisinel PA, Chevalier I, Rallu F, et al. Invasive pneumococcal disease after implementation of a reduced threedose pneumococcal conjugate vaccine program: a pediatric tertiary care center experience. Eur J Pediatr 2010; 169: 1311-5.

36. Dinleyici EC, Kurogol Z. $6^{\text {th }}$ world congress of the World Society for Pediatric Infectious Diseases (WSPID). Expert Rev Vaccines 2010; 9: 261-72.

37. Spijkerman J, van Gils EJ, Veenhoven RH. Carriage of Streptococcus pneumoniae 3 years after start of vaccination program, the Netherlands. Emerg Infect Dis 2011; 17: 584-91.

38. Kaye P, Malkani R, Martin S, et al. Invasive pneumococcal disease (IPD) in England \& Wales after 7-valent conjugate vaccine (PCV7); potential impact of 10 and 13-valent vaccines. http://www.hpa.org.uk/web/HPAwebFile/ HPAweb_C/1245581527892 (accessed 1 July 2010).

39. Surveillence de maladies infectieuses pédiatriques en Belgique, 2007. http://www.iph.fgov.be/epidemio/epifr/ plabfr/eradi07fr.pdf (accessed 1 July 2010).

40. Vestrheim DF, Løvoll O, Aaberge IS, et al. Effectiveness of a $2+1$ dose schedule pneumococcal conjugate vaccination programme on invasive pneumococcal disease among children in Norway. Vaccine 2008; 26: 3277-81.

41. De carvalho Gomes $H$, Muscat M, Monnet DL, et al. Use of 7-valent pneumococcal conjugate vaccine (PCV7) in Europe, 2001-2007. Euro Surveill 2009; 14: 1-6.

42. Vestrheim DF, Høiby EA, Bergsaker MR, et al. Indirect effect of conjugate pneumococcal vaccination in a $2+1$ dose schedule. Vaccine 2010; 28: 2214-21.

43. Paradiso PR. Advances in pneumococcal disease prevention: 13-valent pneumococcal conjugate vaccine for infants and children. Clin Infect Dis 2011; 52: 1241-7.

44. Prevenar 13: EPAR - product information, 2010. http:// www.ema.europa.eu/ema/index.jsp?curl=pages/medicine s/human/medicines/001104/human med 001220.jsp\&m url=menus/medicines/medicines.jsp\&mid=WC0b01ac058 001d124 (accessed 31 June 2010). 